\title{
The correlation between type 2 diabetes and fat fraction in liver and pancreas: a study using MR Dixon technique
}

\author{
Yu Shun (D 76429310@qq.com ) \\ Fujian Provincial Hospital \\ Iv Jieqin \\ Southern Medical University \\ Zhang zhongshuai \\ Siemens Healthcare Limited \\ Ma Mingping \\ Fujian Provincial Hospital
}

Su Jiawei

Fujian Provincial Hospital

Technical advance

Keywords: MR Dixon, type 2 diabetes, obesity, fat fraction in liver and pancreas

Posted Date: August 3rd, 2021

DOI: https://doi.org/10.21203/rs.3.rs-764415/v1

License: (c) (i) This work is licensed under a Creative Commons Attribution 4.0 International License. Read Full License 


\section{Abstract \\ Background}

The increased obesity results in ectopic fat deposits in liver and pancreas.Ectopic fat deposits affect insulin resistance and blood sugar content with Type 2 Diabetes. To assess the relationship between obesity and ectopic fat deposits and diabetes,this study used MR Dixon method for the quantification of liver and pancreas fat fraction (FF) in T2DM patients and healthy controls.

\section{Methods}

The FF of liver and pancreas, the maximum diameters of the pancreas, SAT, VAT and TAT were measured for 167 subjects using the MR Dixon data.Four groups were established on the basis of BMI value.For statistics, intra-and inter-group comparison was done by employing Independent Sample t Test.

\section{Results}

$\otimes$ The average fat content in liver and pancreas, the fat content in pancreas body and tail, and VAT in Group 1 were higher than those in Group 3 (Pख0.05). $\otimes$ The average fat content in liver and pancreas, the adipose fraction of the pancreas head, and VAT in the Group 2 were higher than those in Group 4 $(P \otimes 0.05)$. $\otimes T$ The average fat content of liver and pancreas, the adipose content of the body and the tail of the pancreas, the abdominal subcutaneous adipose area (SAT), the visceral adipose tissue area (VAT), and the total abdominal adipose tissue area (TAT) in Group 2 were higher than those in the Group 1 $(P \otimes 0.05)$. $\otimes$ The FF of pancreas tail, SAT and TAT in Group 4 were higher than those in Group 3 (P囚0.05).

\section{Conclusion}

The tissue FF, which has a close relationship with T2DM,can be assessed by MR Dixon technique.The results showed that all T2DM patients should pay attention to tissue fat content regardless of BMI values.

\section{Background}

Obesity increases the amount of free fatty acids in the body. When normal adipose tissue cannot withstand excess fatty acids, fat accumulates into non-adipose tissue, such as in liver and pancreas, resulting in ectopic fat deposits [1]. Previous studies [1-3] demonstrated that such ectopic fatty infiltration in the liver produces lipotoxic substances, and the high fat concentration in liver among diabetic patients affects insulin resistance, blood sugar content and metabolic control; fat deposit can also cause anatomical changes and abnormal secretion functions of the pancreas, leading to insulin resistance and blood sugar increase in the body.There is a close relationship between obesity and lipid 
metabolism disorders and diabetes, and thus, tissue fat quantification technique is highly required in clinical practice.

Liver and pancreas biopsy is considered as the gold standard for tissue fat quantification. However, performing lipid quantification through biopsy has some disadvantages. For example, such an invasive method may cause bleeding and infection. For another, biopsy only takes a small piece of the tissue for fat content measurement that cannot reflect the condition of the whole target tissue. Further, the pancreas is a peritoneal organ, easily interfered by other organs and the intestinal gas in the abdominal cavity during biopsy. All the demerits mentioned above limit the clinical application of biopsy in liver and pancreas for fat quantification purposes [4].

The medical imaging methods, including ultrasound, computed tomography (CT) and magnetic resonance imaging (MRI), are commonly used clinically for evaluating the fat content of liver and pancreas. Ultrasound examination relies on the operator's experience and lacks objective criteria, and the imaged field of view is also limited. Its diagnostic accuracy of mild and moderate fatty liver is poor, and thus cannot be used for accurate visceral fat quantification $[3,5,6]$.CT is a semi-quantitative method with good repeatability and has a high specificity for the diagnosis of moderate and severe liver fat deposit. However, there are also some limitations of applying CT for fat quantification. Firstly, for monitoring the fat content changes for diabetes patients, CT is not suitable for a follow-up study due to the ionizing radiation. Secondly, CT has a low diagnostic sensitivity to low grade fatty liver. Thirdly, CT value is sensitive to iron deposition in tissue, which may lead to an inaccurate measurement $[7,8]$.

With the development of magnetic resonance imaging (MRI) acquisition and reconstruction technology, MR Dixon method is performed in routine clinical practice for water-fat separation. Previous studies have proved that it can also be used for fat quantification non-invasively, the results of which consist with that of biopsy and have a higher accuracy and specificity than those of CT and ultrasound [9-11]. Trond Engjom[12] demonstrated MR Dixon is superior than ultrasound in evaluating the fat content of pancreas and the corresponding fat fraction (FF) result can be used as a marker of pancreatic secretion of adrenal failure. The purpose of this study was to quantify FF in liver and pancreas using MR Dixon, and to further explore the differences of fat content between type 2 diabetes mellitus (T2DM) patients and healthy volunteers and the differences of fat content between obese T2DM patients and non-obese T2DM patients.

\section{Methods}

\subsection{Patient Population}

This study was approved by our institutional review board of Fujian Provincial Hospital (K2016-04-015) (Fuzhou, Fujian, China) and written informed consent was waived due to its retrospective nature. From May 2016 to December 2020, 118 T2DM patients(72 males and 46 females, Age:18-85 years old, average age 57.07, standard deviation 13.41)received treatment in our hospital (confirmed according to criteria for diagnosing diabetes WTO 1999) and 39 healthy volunteers (10 males and 29 females, 
Age:30-76 years old, average age 52.33 , standard deviation 12.03 were enrolled in this study. BMI, fasting blood glucose, High-density lipoprotein(HDL), Low-density lipoprotein(LDL), Triglyceride(TG)and Cholesterol(CHOL) were acquired for all the patients and volunteers. The exclusion criteria were: 1) patients with type 1 diabetes or other special type diabetes, 2) alcohol intake: male $\geq 140 \mathrm{~g} /$ week or female $\geq 70 \mathrm{~g} /$ week, 3) patients confirmed with iron overload in liver or pancreas or received blood transfusion, 4) patients with chronic pancreatitis, pancreatic cancer, or patients with other disease which can cause fat deposition in pancreas, 5) a contraindication to MR imaging, 6) MR image quality is not sufficient for fat content calculation.

According to the criterion of the Chinese Diabetes Society, a BMI value higher than 25 was defined as obesity. All the subjects were divided into 4 groups, including Group 1: T2DM with BMI 25 (37 males and 24 females, average age 59.28), Group 2: T2DM with BMI $\geq 25$ (35 males and 22 females, average age 54.44), Group 3: control group with BMI $₫ 25$ (6 males and 22 females, average age 51.86) and Group 4: control group with $\mathrm{BMI} \geq 25$ (4 males and 7 females, average age 53.55).

2.2 MR imaging acquisition

All the MR exams were conducted on a 1.5T system (MAGNETOM Aera, SIEMENS Healthcare,Erlangen,Germany).Dual echo 3D VIBE sequence was performed for fat quantification purpose, the detailed parameters were: TR $6.46 \mathrm{~ms}$, TE1/TE2 2.39/4.77ms, FOV 380×380mm, in-plane resolution $1.3 \times 1.3 \mathrm{~mm}$, slice thickness $3 \mathrm{~mm}$ and acquisition time $15 \mathrm{~s}$. In order to reduce the motion artifacts, all patients were informed to hold breath during the data acquisition of the dual echo VIBE sequence.

\subsection{Measurement of FF of liver and pancreas}

For liver, 8 regions of interest (ROIs, with a size of $3 \mathrm{~cm}^{2}$ ) were depicted in left lateral lobe, left medial lobe, right anterior lobe and right posterior lobe in the slice containing main portal vein and two slices below porta hepatis, respectively(figure1), by avoiding bile ducts,large vessels,lesions, the border of the liver and image artifacts. The average value of the eight ROls was noted as the FF in whole liver (FFWL). In this study, we define FFWL $₫ 5 \%, 5 \% \leq \mathrm{FFWL} \otimes 15 \%, 15 \% \leq \mathrm{FFWL} \otimes 25 \%$ and FFWL $\geq 25 \%$ as normal, mild, medium and heavy fat content, respectively. Further, 4 ROls (with a size of around $1.5 \mathrm{~cm}^{2}$ ) were located in head, neck, body and tail of the pancreas $\square$ figure2), respectively, the average value of which was considered as the FF of whole pancreas (FFWP). The maximum diameters of the pancreas head, neck, body and tail were recorded using the dual-echo VIBE images, and the average diameter of pancreas was also calculated using the three diameters mentioned above. All the measurements mentioned above were conducted on a commercial workstation (SIEMENS Healthcare, Erlangen, Germany).

\subsection{Measurement of abdominal fat area}

The abdominal subcutaneous adipose area (SAT) and the visceral adipose tissue area (VAT) were measured using the FF image, which is $8 \mathrm{~cm}$ higher than the L4-L5 intervertebral space, by an open 
source software (ImageJ,https://imagej.nih.gov/ij/index.html). The total abdominal adipose tissue area (TAT) was calculated by adding SAT and VAT(Fig. 3).

\subsection{Statistical analysis}

The statistical analysis was performed with SPSS (version 22.0, SPSS inc., Chicago, IL, USA). The measured numerical data was presented as mean \pm standard deviation. Intra- and inter-group comparison was done by employing Independent Sample t Test. The variance analysis was used to compare the fat content of the four study groups, and post-hoc test was conducted with regard to the variables with significant difference in the four groups. Univariate logistic regression was used for all the variate, and then, multivariate logistic regression was conducted with respect to the variate with statistic differences, so as to determine the independent predictor. $\mathrm{P}$ value $\mathbb{0} 0.05$ was considered as statistic significant.

\section{Results}

\subsection{Comparison between Group 1, Groug 2, Group 3 and Group 4.}

\subsubsection{Comparison between Group 1 and Group 3}

The values of FBG, TG, FFWL, FFWP, and the FF of the body and the tail of the pancreas and VAT in Group 1 were all higher than those in Group 3 (shown in Table 1). Univariate logistic regression indicated that, for patients and volunteers with $B M I$ lower than 25, $F B G(B=1.59, \operatorname{Exp}(B)=4.94, P=0.00), T G(B=0.99$, $\operatorname{Exp}(B)=2.70, P=0.02), F F W L(B=0.21, \operatorname{Exp}(B)=1.23, P=0.01), F F W P(B=0.23, \operatorname{Exp}(B)=1.26, P=0.02)$, the $F F$ of pancreas body $(B=1.60, \operatorname{Exp}(B)=1.17, P=0.04)$, the $F F$ of pancreas tail $(B=0.22, \operatorname{Exp}(B)=1.24$, $P=0.01)$, and VAT $(B=0.01, \operatorname{Exp}(B)=1.01, P=0.02)$ are the risk factors for T2DM. Multivariate logistic regression indicated that $F B G$ is the independent predictor for people with $B M I$ lower than $25(B=$ $1.59, \operatorname{Exp}(B)=4.94, P=0.00$ ). 
Table 1

Comparison of tissue FF and clinical indicators between Group 1 and Group 3

\begin{tabular}{|llll|}
\hline & Group 3 & Group 1 & P \\
\hline FBG $(\mathrm{mmol} / \mathrm{L})$ & $4.93 \pm 0.66$ & $8.83 \pm 3.47$ & 0.00 \\
\hline $\mathrm{HDL}(\mathrm{mmol} / \mathrm{L})$ & $1.50 \pm 0.86$ & $1.19 \pm 0.44$ & 0.03 \\
\hline $\mathrm{LDL}(\mathrm{mmol} / \mathrm{L})$ & $2.76 \pm 0.97$ & $3.03 \pm 0.93$ & 0.23 \\
\hline $\mathrm{TG}(\mathrm{mmol} / \mathrm{L})$ & $1.09 \pm 0.49$ & $1.75 \pm 1.41$ & 0.00 \\
\hline $\mathrm{CHOL}(\mathrm{mmol} / \mathrm{L})$ & $4.35 \pm 1.09$ & $4.73 \pm 1.10$ & 0.14 \\
\hline FFWL(\%) & $4.17 \pm 2.52$ & $7.86 \pm 5.95$ & 0.00 \\
\hline FF of pancreas head(\%) & $6.81 \pm 4.69$ & $7.63 \pm 3.84$ & 0.38 \\
\hline FF of pancreas neck(\%) & $7.52 \pm 3.45$ & $9.11 \pm 3.86$ & 0.06 \\
\hline FF of pancreas body(\%) & $7.12 \pm 2.67$ & $8.88 \pm 4.10$ & 0.04 \\
\hline FF of pancreas tail(\%) & $6.91 \pm 2.11$ & $9.10 \pm 4.47$ & 0.00 \\
\hline FFWP(\%) & $7.09 \pm 2.60$ & $8.68 \pm 3.00$ & 0.01 \\
\hline Average diameter of pancreas(cm) & $1.64 \pm 0.29$ & $1.84 \pm 1.79$ & 0.56 \\
\hline SAT $\left(\mathrm{cm}^{2}\right)$ & $91.46 \pm 39.48$ & $88.05 \pm 39.44$ & 0.70 \\
\hline VAT $\left(\mathrm{cm}^{2}\right)$ & $69.36 \pm 54.77$ & $97.13 \pm 47.74$ & 0.01 \\
\hline TAT $\left(\mathrm{cm}^{2}\right)$ & $160.82 \pm 81.15$ & $185.19 \pm 61.41$ & 0.11 \\
\hline
\end{tabular}

3.1.2 Comparison between Group 2 and Group 4

The values of FBG, TG, CHOL, FFWL, FFWP, the FF of the head of pancreas and VAT in Group 2 are all higher than those in Group 4 (shown in Table 2). Through univariate logistic regression, it is indicated that, $F B G(B=2.30, \operatorname{Exp}(B)=10.03, P=0.00), \operatorname{HLD}(B=-2.25, \operatorname{Exp}(B)=0.10, P=0.02), F F W(B=0.17$, $\operatorname{Exp}(B)=1.19, P=0.03)$ and VAT $(B=0.01, \operatorname{Exp}(B)=1.01, P=0.01)$ are the predictors for T2DM. The multivariate logistic regression analysis indicated that $F B G(B=3.52, \operatorname{Exp}(B)=33.84, P=0.02)$ and $F F W P$ $(B=0.72, \operatorname{Exp}(B)=2.06, P=0.02)$ are the independent predictors for people with $B M I \geq 25$. 
Table 2

Comparison of tissue FF and clinical indicators between Group 2 and Group 4

\begin{tabular}{|llll|}
\hline & Group 4 & Group 2 & P \\
\hline FBG $(\mathrm{mmol} / \mathrm{L})$ & $5.45 \pm 0.60$ & $9.06 \pm 2.75$ & 0.00 \\
\hline $\mathrm{HDL}(\mathrm{mmol} / \mathrm{L})$ & $1.24 \pm 0.48$ & $0.98 \pm 0.27$ & 0.12 \\
\hline $\mathrm{LDL}(\mathrm{mmol} / \mathrm{L})$ & $3.17 \pm 0.77$ & $3.10 \pm 0.98$ & 0.82 \\
\hline $\mathrm{TG}(\mathrm{mmol} / \mathrm{L})$ & $1.79 \pm 0.78$ & $5.13 \pm 7.15$ & 0.00 \\
\hline $\mathrm{CHOL}(\mathrm{mmol} / \mathrm{L})$ & $4.79 \pm 0.56$ & $5.65 \pm 2.13$ & 0.01 \\
\hline FFWL(\%) & $6.04 \pm 3.63$ & $13.85 \pm 9.18$ & 0.00 \\
\hline FF of pancreas head(\%) & $6.50 \pm 2.15$ & $8.69 \pm 4.69$ & 0.02 \\
\hline FF of pancreas neck(\%) & $7.86 \pm 2.47$ & $9.07 \pm 5.95$ & 0.51 \\
\hline FF of pancreas body(\%) & $9.00 \pm 3.54$ & $10.83 \pm 4.81$ & 0.23 \\
\hline FF of pancreas tail(\%) & $8.94 \pm 2.25$ & $11.19 \pm 5.19$ & 0.16 \\
\hline FFWP(\%) & $8.08 \pm 1.95$ & $9.95 \pm 3.87$ & 0.02 \\
\hline Average diameter of pancreas(cm) & $1.67 \pm 0.35$ & $2.18 \pm 1.86$ & 0.37 \\
\hline SAT (cm $\left.{ }^{2}\right)$ & $137.96 \pm 84.95$ & $124.72 \pm 67.74$ & 0.57 \\
\hline VAT $\left(\mathrm{cm}^{2}\right)$ & $108.03 \pm 51.75$ & $172.22 \pm 77.42$ & 0.01 \\
\hline TAT $\left(\mathrm{cm}^{2}\right)$ & $245.99 \pm 119.63$ & $296.94 \pm 116.10$ & 0.19 \\
\hline
\end{tabular}

3.1.3 Comparison between Group 1 and Group 2

For T2DM patients, TG, CHOL, FFWL, FFWP, FF of the head and tail of pancreas, SAT, VAT and TAT in Group 2 were all higher than those in Group 1, and HDL of Group 1 is lower than that of Group 2 (shown in Table 3). 
Table 3

Comparison of tissue FF and clinical indicators between Group 1 and Group 2

\begin{tabular}{|llll|}
\hline & Group 1 & Group 2 & P \\
\hline FBG(mmol/L) & $8.83 \pm 3.47$ & $9.06 \pm 2.75$ & 0.69 \\
\hline $\mathrm{HDL}(\mathrm{mmol} / \mathrm{L})$ & $1.19 \pm 0.44$ & $0.98 \pm 0.27$ & 0.00 \\
\hline $\mathrm{LDL}(\mathrm{mmol} / \mathrm{L})$ & $3.03 \pm 0.93$ & $3.10 \pm 0.98$ & 0.67 \\
\hline $\mathrm{TG}(\mathrm{mmol} / \mathrm{L})$ & $1.75 \pm 1.41$ & $5.13 \pm 7.15$ & 0.00 \\
\hline $\mathrm{CHOL}(\mathrm{mmol} / \mathrm{L})$ & $4.73 \pm 1.10$ & $5.65 \pm 2.13$ & 0.00 \\
\hline FFWL(\%) & $7.86 \pm 5.95$ & $13.85 \pm 9.18$ & 0.00 \\
\hline FF of pancreas head(\%) & $7.63 \pm 3.84$ & $8.69 \pm 4.69$ & 0.17 \\
\hline FF of pancreas neck(\%) & $9.11 \pm 3.86$ & $9.07 \pm 5.95$ & 0.96 \\
\hline FF of pancreas body(\%) & $8.88 \pm 4.10$ & $10.83 \pm 4.81$ & 0.01 \\
\hline FF of pancreas tail(\%) & $9.10 \pm 4.47$ & $11.19 \pm 5.19$ & 0.02 \\
\hline Average FF of pancreas(\%) & $8.68 \pm 3.00$ & $9.95 \pm 3.87$ & 0.04 \\
\hline Average diameter of pancreas(cm) & $1.84 \pm 1.79$ & $2.18 \pm 1.86$ & 0.31 \\
\hline SAT(cm $\left.{ }^{2}\right)$ & $88.05 \pm 39.44$ & $124.72 \pm 67.74$ & 0.00 \\
\hline VAT(cm $\left.{ }^{2}\right)$ & $97.13 \pm 47.74$ & $172.22 \pm 77.42$ & 0.00 \\
\hline TAT( $\mathrm{cm}^{2}$ ) & $185.19 \pm 61.41$ & $296.94 \pm 116.10$ & 0.00 \\
\hline
\end{tabular}

3.1.4 Comparison between Group 2 and Group 4

For control group, FPG, TG, CHOL, FF of the tail of pancreas, SAT and TAT in Group 2(BMI $\geq 25)$ were all higher than those in Group 1(BMI 25 )(shown in Table 4). 
Table 4

Comparison of tissue FF and clinical indicators between Group 2 and Group 4

\begin{tabular}{|llll|}
\hline & Group3 & Group 4 & P \\
\hline FPG $(\mathrm{mmol} / \mathrm{L})$ & $4.93 \pm 0.66$ & $5.45 \pm 0.60$ & 0.031 \\
\hline $\mathrm{HDL}(\mathrm{mmol} / \mathrm{L})$ & $1.50 \pm 0.86$ & $1.24 \pm 0.48$ & 0.385 \\
\hline $\mathrm{LDL}(\mathrm{mmol} / \mathrm{L})$ & $2.76 \pm 0.97$ & $3.17 \pm 0.77$ & 0.223 \\
\hline $\mathrm{TG}(\mathrm{mmol} / \mathrm{L})$ & $1.09 \pm 0.49$ & $1.79 \pm 0.78$ & 0.002 \\
\hline $\mathrm{CHLO}(\mathrm{mmol} / \mathrm{L})$ & $4.35 \pm 1.09$ & $4.79 \pm 0.56$ & 0.120 \\
\hline FF of pancreas head(\%) & $6.81 \pm 4.69$ & $6.50 \pm 2.15$ & 0.838 \\
\hline FF of pancreas neck(\%) & $7.52 \pm 3.45$ & $7.86 \pm 2.47$ & 0.767 \\
\hline FF of pancreas body(\%) & $7.12 \pm 2.67$ & $9.00 \pm 3.54$ & 0.079 \\
\hline FF of pancreas tail(\%) & $6.91 \pm 2.11$ & $8.94 \pm 2.25$ & 0.012 \\
\hline Average FF of pancreas(\%) & $7.09 \pm 2.60$ & $8.08 \pm 1.95$ & 0.264 \\
\hline Average diameter of pancreas(cm) & $1.64 \pm 0.29$ & $1.67 \pm 0.35$ & 0.799 \\
\hline SAT $\left(\mathrm{cm}^{2}\right)$ & $91.46 \pm 39.48$ & $137.96 \pm 84.95$ & 0.024 \\
\hline VAT $\left(\mathrm{cm}^{2}\right)$ & $69.36 \pm 54.77$ & $108.03 \pm 51.75$ & 0.051 \\
\hline TAT $\left(\mathrm{cm}^{2}\right)$ & $160.82 \pm 81.15$ & $245.99 \pm 119.63$ & 0.014 \\
\hline
\end{tabular}

3.2 Comparison between T2DM patients and volunteers with normal liver fat content

As shown in Table 5, for subjects with normal liver fat content, FBG, FFWP, FF of pancreas tail and VAT of T2DM patients were higher than those of control volunteers. 
Table 5

Comparison between T2DM patients and volunteers with normal liver fat content

\begin{tabular}{|llll|}
\hline & Volunteers & T2DM patients & P \\
\hline FBG $(\mathrm{mmol} / \mathrm{L})$ & $5.12 \pm 0.68$ & $8.55 \pm 3.48$ & 0.00 \\
\hline $\mathrm{HDL}(\mathrm{mmol} / \mathrm{L})$ & $1.54 \pm 0.83$ & $1.23 \pm 0.43$ & 0.04 \\
\hline $\mathrm{LDL}(\mathrm{mmol} / \mathrm{L})$ & $2.86 \pm 0.91$ & $2.90 \pm 0.91$ & 0.85 \\
\hline $\mathrm{TG}(\mathrm{mmol} / \mathrm{L})$ & $1.25 \pm 0.66$ & $1.36 \pm 0.77$ & 0.54 \\
\hline $\mathrm{CHOL}(\mathrm{mmol} / \mathrm{L})$ & $4.53 \pm 1.00$ & $4.48 \pm 0.98$ & 0.84 \\
\hline FF of pancreas head(\%) & $6.36 \pm 3.61$ & $7.83 \pm 4.11$ & 0.12 \\
\hline F of pancreas neck(\%) & $7.49 \pm 3.05$ & $8.35 \pm 4.53$ & 0.37 \\
\hline FF of pancreas body(\%) & $7.30 \pm 3.19$ & $8.08 \pm 3.40$ & 0.32 \\
\hline FF of pancreas tail(\%) & $7.41 \pm 2.28$ & $9.83 \pm 5.29$ & 0.00 \\
\hline FFWP(\%) & $7.14 \pm 2.38$ & $8.52 \pm 3.00$ & 0.04 \\
\hline Average diameter of pancreas(cm) & $1.64 \pm 0.30$ & $1.64 \pm 0.31$ & 0.90 \\
\hline SAT $\left(\mathrm{cm}^{2}\right)$ & $93.35 \pm 45.30$ & $91.63 \pm 44.93$ & 0.87 \\
\hline VAT $\left(\mathrm{cm}^{2}\right)$ & $65.62 \pm 48.22$ & $100.58 \pm 63.65$ & 0.01 \\
\hline TAT $\left(\mathrm{cm}^{2}\right)$ & $158.97 \pm 82.63$ & $192.21 \pm 81.09$ & 0.09 \\
\hline
\end{tabular}

3.3 Comparison between T2DM patients and volunteers with mild liver fat content

As shown in Table 6, for subjects with mild liver fat content, FBG, FFWP, FF of pancreas neck and tail of T2DM patients were higher than those of control volunteers. 
Table 6

Comparison between T2DM patients and volunteers with mild liver fat content

\begin{tabular}{|llll|}
\hline & Volunteers & T2DM patients & P \\
\hline FBG $(\mathrm{mmol} / \mathrm{L})$ & $5.02 \pm 0.70$ & $9.20 \pm 3.19$ & 0.00 \\
\hline $\mathrm{HDL}(\mathrm{mmol} / \mathrm{L})$ & $1.09 \pm 0.44$ & $0.99 \pm 0.36$ & 0.49 \\
\hline $\mathrm{LDL}(\mathrm{mmol} / \mathrm{L})$ & $2.97 \pm 0.99$ & $2.97 \pm 1.08$ & 0.99 \\
\hline $\mathrm{TG}(\mathrm{mmol} / \mathrm{L})$ & $1.49 \pm 0.69$ & $3.75 \pm 6.38$ & 0.29 \\
\hline $\mathrm{CHOL}(\mathrm{mmol} / \mathrm{L})$ & $4.35 \pm 0.92$ & $5.06 \pm 1.94$ & 0.29 \\
\hline FF of pancreas head(\%) & $7.77 \pm 5.40$ & $9.69 \pm 4.04$ & 0.22 \\
\hline FF of pancreas neck(\%) & $7.99 \pm 3.67$ & $11.46 \pm 4.22$ & 0.02 \\
\hline FF of pancreas body(\%) & $8.68 \pm 2.26$ & $11.26 \pm 5.67$ & 0.16 \\
\hline FF of pancreas tail(\%) & $7.69 \pm 2.50$ & $11.85 \pm 6.19$ & 0.04 \\
\hline Average FF of pancreas(\%) & $8.03 \pm 2.66$ & $11.07 \pm 3.89$ & 0.02 \\
\hline Average diameter of pancreas(cm) & $1.70 \pm 0.33$ & $1.68 \pm 0.30$ & 0.84 \\
\hline SAT $\left(\mathrm{cm}^{2}\right)$ & $137.15 \pm 81.38$ & $109.23 \pm 58.77$ & 0.23 \\
\hline VAT $\left(\mathrm{cm}^{2}\right)$ & $122.73 \pm 57.97$ & $140.35 \pm 62.39$ & 0.43 \\
\hline TAT $\left(\mathrm{cm}^{2}\right)$ & $259.88 \pm 111.21$ & $249.58 \pm 89.67$ & 0.76 \\
\hline
\end{tabular}

3.4 Comparison between T2DM patients with different liver fat content

According to the liver fat content, T2DM patients were separated into normal, mild, medium and heavy groups. After post-hoc test analysis, the results of all the parameters were: HDL normal $\square$ mildnheavy,

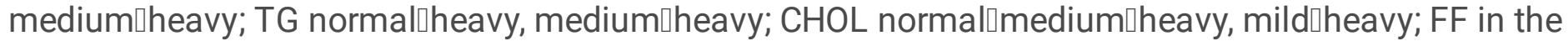
head of pancreas normal, mild and medium $\square$ heavy; FF in the neck of pancreas heavy $\square$ normal $\square$ mild, medium $\square$ heavy; FF in the body of pancreas mild and medium $\llbracket$ normal, heavy $\square$ mild; FF of the whole pancreas mild $\llbracket$ normal[heavy, medium $\square$ heavy; Average diameter of pancreas heavy $\llbracket$ normal, mild; VAT

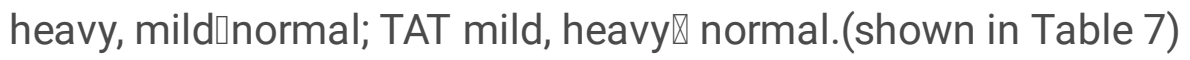


Table 7

Comparison between T2DM patients with different liver fat content

normal mild medium Heavy $F \quad P \quad \begin{aligned} & \text { post-hoc test } \\ & \text { analysis }\end{aligned}$

\begin{tabular}{|c|c|c|c|c|c|c|c|}
\hline $\mathrm{FBG}(\mathrm{mmol} / \mathrm{L})$ & $\begin{array}{l}8.55 \pm \\
3.48\end{array}$ & $\begin{array}{l}9.20 \pm \\
3.19\end{array}$ & $\begin{array}{l}9.40 \pm \\
3.23\end{array}$ & $\begin{array}{l}8.78 \pm \\
1.99\end{array}$ & 0.46 & 0.70 & \\
\hline $\mathrm{HDL}(\mathrm{mmol} / \mathrm{L})$ & $\begin{array}{l}1.23 \pm \\
0.43\end{array}$ & $\begin{array}{l}0.99 \pm \\
0.36\end{array}$ & $\begin{array}{l}1.19 \pm \\
0.30\end{array}$ & $\begin{array}{l}0.83 \pm \\
0.16\end{array}$ & 6.76 & 0.00 & $\begin{array}{l}\text { normal }>\text { mild > } \\
\text { heavy;medium > } \\
\text { heavy }\end{array}$ \\
\hline LDL(mmol/L) & $\begin{array}{l}2.90 \pm \\
0.91\end{array}$ & $\begin{array}{l}2.97 \pm \\
1.08\end{array}$ & $\begin{array}{l}3.43 \pm \\
1.04\end{array}$ & $\begin{array}{l}3.17 \pm \\
0.43\end{array}$ & 1.73 & 0.16 & \\
\hline $\mathrm{TG}(\mathrm{mmol} / \mathrm{L})$ & $\begin{array}{l}1.36 \pm \\
0.77\end{array}$ & $\begin{array}{l}3.75 \pm \\
6.38\end{array}$ & $\begin{array}{l}2.04 \pm \\
1.36\end{array}$ & $\begin{array}{l}8.93 \pm \\
7.76\end{array}$ & 11.69 & 0.00 & $\begin{array}{l}\text { normal < heavy; } \\
\text { medium < heavy }\end{array}$ \\
\hline $\mathrm{CHOL}(\mathrm{mmol} / \mathrm{L})$ & $\begin{array}{l}4.48 \pm \\
0.98\end{array}$ & $\begin{array}{l}5.06 \pm \\
1.94\end{array}$ & $\begin{array}{l}5.23 \pm \\
1.05\end{array}$ & $\begin{array}{l}6.90 \pm \\
2.18\end{array}$ & 10.17 & 0.00 & $\begin{array}{l}\text { normal }<\text { medium }< \\
\text { heavy;mild }<\text { heavy }\end{array}$ \\
\hline $\begin{array}{l}\text { FF of pancreas } \\
\text { head }(\%)\end{array}$ & $\begin{array}{l}7.83 \pm \\
4.11\end{array}$ & $\begin{array}{l}9.69 \pm \\
4.04\end{array}$ & $\begin{array}{l}8.84 \pm \\
5.01\end{array}$ & $\begin{array}{l}4.71 \pm \\
0.93\end{array}$ & 6.17 & 0.00 & $\begin{array}{l}\text { normal,mild } \square \text { medium } \\
>\text { heavy }\end{array}$ \\
\hline $\begin{array}{l}\text { FF of pancreas } \\
\text { neck }(\%)\end{array}$ & $\begin{array}{l}8.35 \pm \\
4.53\end{array}$ & $\begin{array}{l}11.46 \\
\pm 4.22\end{array}$ & $\begin{array}{l}11.32 \pm \\
4.40\end{array}$ & $\begin{array}{l}3.29 \pm \\
1.05\end{array}$ & 17.85 & 0.00 & $\begin{array}{l}\text { heavy }<\text { normal }< \\
\text { mild;medium }>\text { heavy }\end{array}$ \\
\hline $\begin{array}{l}\text { FF of pancreas } \\
\text { body }(\%)\end{array}$ & $\begin{array}{l}8.08 \pm \\
3.40\end{array}$ & $\begin{array}{l}11.26 \\
\pm 5.67\end{array}$ & $\begin{array}{l}11.64 \pm \\
4.94\end{array}$ & $\begin{array}{l}8.65 \pm \\
0.36\end{array}$ & 5.51 & 0.00 & $\begin{array}{l}\text { mild,medium > } \\
\text { normal,heavy < } \\
\text { medium }\end{array}$ \\
\hline $\begin{array}{l}\text { FF of pancreas } \\
\text { tail(\%) }\end{array}$ & $\begin{array}{l}9.83 \pm \\
5.29\end{array}$ & $\begin{array}{l}11.85 \\
\pm 6.19\end{array}$ & $\begin{array}{l}8.74 \pm \\
2.74\end{array}$ & $\begin{array}{l}8.86 \pm \\
0.71\end{array}$ & 2.52 & 0.06 & $\begin{array}{l}\text { mild > } \\
\text { normal;medium < } \\
\text { normallnheavy > } \\
\text { medium }\end{array}$ \\
\hline FFWP(\%) & $\begin{array}{l}8.52 \pm \\
3.00\end{array}$ & $\begin{array}{l}11.07 \\
\pm 3.89\end{array}$ & $\begin{array}{l}10.14 \pm \\
3.16\end{array}$ & $\begin{array}{l}6.38 \pm \\
0.67\end{array}$ & 10.03 & 0.00 & $\begin{array}{l}\text { mild }>\text { normal }> \\
\text { heavy;medium }> \\
\text { heavy }\end{array}$ \\
\hline $\begin{array}{l}\text { Average } \\
\text { diameter of } \\
\text { pancreas }(\mathrm{cm})\end{array}$ & $\begin{array}{l}1.64 \pm \\
0.31\end{array}$ & $\begin{array}{l}1.68 \pm \\
0.30\end{array}$ & $\begin{array}{l}2.86 \pm \\
4.00\end{array}$ & $\begin{array}{l}2.37 \pm \\
0.29\end{array}$ & 2.99 & 0.03 & heavy > normal,mild \\
\hline SAT(cm2) & $\begin{array}{l}91.63 \\
\pm 44.93\end{array}$ & $\begin{array}{l}109.23 \\
\pm 58.77\end{array}$ & $\begin{array}{l}114.87 \\
\pm 82.36\end{array}$ & $\begin{array}{l}116.63 \\
\pm 33.15\end{array}$ & 1.34 & 0.26 & \\
\hline $\operatorname{VAT}\left(\mathrm{cm}^{2}\right)$ & $\begin{array}{l}100.58 \\
\pm 63.65\end{array}$ & $\begin{array}{l}140.35 \\
\pm 62.39\end{array}$ & $\begin{array}{l}134.41 \\
\pm 64.29\end{array}$ & $\begin{array}{l}189.85 \\
\pm 90.14\end{array}$ & 7.46 & 0.00 & heavy,mild > normal \\
\hline $\operatorname{TAT}\left(\mathrm{cm}^{2}\right)$ & $\begin{array}{l}192.21 \\
\pm 81.09\end{array}$ & $\begin{array}{l}249.58 \\
\pm 89.67\end{array}$ & $\begin{array}{l}249.2 \pm \\
125.68\end{array}$ & $\begin{array}{l}306.48 \\
\pm \\
123.23\end{array}$ & 5.97 & 0.00 & mild,heavy > normal \\
\hline SFP & $\begin{array}{l}0.50 \pm \\
0.17\end{array}$ & $\begin{array}{l}0.43 \pm \\
0.13\end{array}$ & $\begin{array}{l}0.45 \pm \\
0.15\end{array}$ & $\begin{array}{l}0.40 \pm \\
0.04\end{array}$ & 2.62 & 0.05 & normal > heavy \\
\hline
\end{tabular}




\begin{tabular}{|c|c|c|c|c|c|c|c|}
\hline & normal & mild & medium & Heavy & $\mathbf{F}$ & $\mathbf{P}$ & $\begin{array}{l}\text { post-hoc test } \\
\text { analysis }\end{array}$ \\
\hline VFP & $\begin{array}{l}0.50 \pm \\
0.17\end{array}$ & $\begin{array}{l}0.57 \pm \\
0.13\end{array}$ & $\begin{array}{l}0.55 \pm \\
0.15\end{array}$ & $\begin{array}{l}0.60 \pm \\
0.04\end{array}$ & 2.62 & 0.05 & heavy $>$ normal \\
\hline
\end{tabular}

\section{Discussions}

With the continuous change of people's lifestyle and diet structure, unhealthy lifestyles, such as long-term intake of fat, lead to excessive accumulation of lipid in the human body. There is a close relationship between ectopic fat deposition and T2DM [1]. Such chronic noncommunicable disease needs early detection, early diagnosis and early treatment, and thus, quantitative technique for tissue fat content is highly required in routine clinical practice.

Liver and pancreas biopsies are considered as the gold standard for fat quantification. However, due to its invasiveness, it is difficult to perform biopsy widely. Medical imaging modalities, like CT and ultrasound, can only be employed for qualitative diagnosis of tissue fat content. And CT exposes patients to ionizing radiation, which is not suitable for long term follow-up treatment. All the limitations indicate that CT and ultrasound are not optimal for accurate tissue FF assessment.

Magnetic Resonance Spectroscopy (MRS) was also used for liver fat quantification in previous paper. However, this study did not employ MRS to measure tissue fat content due to two reasons. Firstly, high field homogeneity is required for MRS exams, not all the MR scanners fulfill this requirement, especially the ones with large diameter. Secondly, current commercial available MRS technique in abdomen can only obtain signal of a single voxel, which cannot reflect fat deposition of the whole target tissue $[2,3,5$, 8]. MR Dixon technology is based on the principle of chemical shift between water and fat. By adjusting the echo time, in-phase and oppose-phase images are acquired within a single breath hold, which can be used for calculating the image of water or fat signals. A previous phantom study demonstrated that Dixon can provide accurate tissue fat content with reliable reproducibility. [13] Therefore, the present study used MR Dixon to derive tissue fat deposition, and further to analyze the fat content of T2DM patients and healthy subjects, and indicators of fat T2DM and normal T2DM patients.

For healthy people, fatty acids are stored in fat tissue in the form of triacylglycerol. When triacylglycerol exceeds the carrying capacity of adipose tissue, fat accumulates into non-fat tissue, such as liver and pancreas. The results of the present study show that the fat content of liver and pancreas of T2DM patients are higher than that of the control group. Previous studies have shown that fat deposition in liver causes insulin resistance, which may result in T2DM. Therefore, the presence of T2DM is highly related to the adipose deposition of liver [14, 15]. In Feng et al's paper [16], the liver FF of T2DM patients was higher than that of the normal subjects, which is consistent with our results. But no difference of pancreas fat content between T2DM and healthy volunteers was observed, that maybe caused by their small sample size. At present, the relationship between pancreatic fat deposition and T2DM is not clear. Both Chai et al [1] and Lu T [17] found that patients with T2DM had higher fat content in pancreas than that of healthy 
people, which agreed with the results in the current study. Fatty pancreas have a higher proportion of T2DM than non-fatty pancreas group, indicating that fatty pancreas may have association with T2DM [18].This study demonstrated that the FF of pancreas head, body and tail in T2DM patients are different from those of healthy volunteers. The univariate logistic regression analysis indicated that the adipose content in pancreas body and tail are the predictors of T2DM. S. Matsumoto et al [19] reported that different parts of pancreas generated from different embryologic pancreatic buds, resulting in the uneven fatty replacement of the pancreas. The posterior aspect of the head and the uncinate process of the pancreas lack adipose cells, but the anterior aspect of the head, the body and the tail of the pancreas are sensitive to fat deposition, which agrees with the results of this study and may have a close relationship with T2DM.

Overweight or obesity is a risk factor for T2DM, but non-obese people may also suffer diabetes. This study found that the FFWL, FFWP and VA are statistically different between NT2DM and NCG. Through the analysis of single-factor logistic, the three indicators above are all influence factors in non-obese people with T2DM. Obesity could also cause dyslipidemia. In this study, for subjects with $B M I \geq 25$, TG and $\mathrm{CHOL}$ of T2DM patients were both higher than those of the corresponding volunteers, Obese diabetic suffer from metabolism disorder, resulting in hyperlipidemia and other complications. Therefore, diabetic patients should pay attention to weight management, so as to prevent hyperlipidemia.

A previous study [20] showed that, higher fasting and post-prandial C-peptide levels and insulin resistance in non-obese patients with T2DM independently associated with intra-abdominal adipose tissue volume. Free fatty acids and pro-inflammatory factors released by tissue fat can cause inflammatory reactions and insulin resistance in liver and pancreas after passing through the portal vein, leading to abnormality of blood sugar[21]. Comparing with subcutaneous fat, fat area in abdominal tissue has a higher correlation with blood glucose metabolism [22]. The findings in this study also demonstrates that VAT of T2DM patients is higher than that of the control group, and with the increase of tissue fat content, the occurrence of metabolic complications also increases[23, 24]. BMI, as the criterion of diagnosing obesity, can only assess the degree of obesity, but not reflect the fat distribution in the human body. Therefore, it is necessary to not only pay attention to the BMI value, but also the tissue fat content when diagnosing T2DM patients.

There are still some limitations in this study. Firstly, the employed dual-echo Dixon sequence is sensitive to field inhomogeneity, which may generate phase error and further affect the accuracy of the FF calculation. On the other hand, ion deposition in the tissue, such as in liver, leads to the decrease of T2*, which introduces calculation errors for fat quantification using dual-echo Dixon method. Such problem can be solved by using multi-echo Dixon technique. Accurate water, FF as well as T2* value can be derived simultaneously by fitting the acquired exponential decay curve. Previous researches [25, 26] showed that the liver fat content generated by a six-echo Dixon sequence had a high association with that obtained by MRS and biopsy, respectively. However, such advanced sequence is not equipped in the employed scanner in this study, and will be used for analyzing the tissue adipose content of T2DM patients in our future plan.

Page 14/21 


\section{Conclusion}

The evaluation of tissue FF plays an important role in the development of diabetes. MR Dixon technique has the clinical potential to quantify the adipose content invasively, which will be helpful for T2DM patients.

\section{Abbreviations}

T2DM: type 2 diabetes; SA: subcutaneous adipose area; VA: visceral adipose area; TA: total abdominal fat area; BMI: body mass index; HDL: high-density lipoprotein; LDL: low-density lipoprotein; TG: triglyceride; CHOL: cholesterol; FFWL:fat fraction in whole liver; FFWP:fat fraction in whole pancreas.

\section{Declarations}

\section{Ethics approval and consent to participate}

This study was conducted in accordance with the ministry of health "involves people of biomedical research ethics review method (try out)" (2007), the food and drug supervision and administration of " the clinical trials of drug quality management norms (2003)," "medical instrument clinical trial regulations " (2004), the world medical association "declaration of Helsinki "(2013), as well as the international medical science organization committee the human body biomedical research international theory guide ethical principles (2002), approved by the Ethics Committee on Fujian Province Hospital (K2016-04-015) (Fuzhou, Fujian, China)..

\section{Consent for publication}

Not applicable

\section{Availability of data and materials}

The datasets during and/or analysed during the current study are available from the corresponding author on reasonable request. All data generated or analysed during this study are included in this published article [and its supplementary information files].

\section{Competing interests}

The authors declare that they have no competing interests.

\section{Funding}

The work presented in this article was supported by Natural Science Foundation of Fujian Province(2017J01172) and China International Medical Foundation (Z-2014-07-1912-14). 
YS designed the work, checked patients, acquisited, analyzed and interpreted the patient data, be accountable for all aspects of the work in ensuring that questions related to the accuracy or integrity of any part of the work are appropriately investigated and resolved.

LJQ acquisited, analyzed and interpreted the patient data, drafted the work.

ZZS acquisited, analyzed and interpreted the patient data.

MMP guided writing of articles.

SJW Checked patients and collected patient information.

All authors read and approved the final manuscript.

\section{Acknowledgements}

Thanks to technician Shengmei Lin and nurse Fang Huang who helped in the MR examination; thanks to Fayang Lian who works in the scientific research department of the hospital to provide scientific consultation.

\section{References}

1. Chai J, Liu P, Hong X, Yin J, Yu H-C, Su T-H et al. Comparative study of pancreatic fat content between newly-diagnosed patients with type 2 diabetes and healthy volunteers by chemical shift magnetic resonance imaging. Chinese Journal of Magnetic Resonance Imaging.2015;3:208-212.

2. Dong Z, Luo Y, Cai H, Zhang Z, Peng Z, Jiang M et al. Noninvasive fat quantification of the liver and pancreas may provide potential biomarkers of impaired glucose tolerance and type 2 diabetes.Medicine.2016;95(23):e3858.

3. Ozturk A, Grajo J R, Gee M S, Benjamin A, Zubajlo R E, Thomenius K E et al. Quantitative hepatic fat quantification in non-alcoholic fatty liver disease using ultrasound-based techniques: a review of literature and their diagnostic performance. Ultrasound in medicine \& biology. 2018; 44: 2461-75.

4. Lv S, Jiang S, Liu S, Dong Q, Xin Y, Xuan S et al. Noninvasive quantitative detection methods of liver fat content in nonalcoholic fatty liver disease. Journal of clinical and translational hepatology. 2018;6(2):217-221.

5. Di Lascio N, Avigo C, Salvati A, Martini N, Ragucci M, Monti S et al. Steato-score: non-invasive quantitative assessment of liver fat by ultrasound imaging. Ultrasound in medicine \& biology. 2018; 44: 1585-96.

6. Lăpădat A M, Jianu I R, Ungureanu B S, Florescu L M, Gheonea D I, Sovaila S et al. Non-invasive imaging techniques in assessing non-alcoholic fatty liver disease: a current status of available methods. Journal of medicine and life. 2017; 10: 19. 
7. Zhang Y N, Fowler K J, Hamilton G, Cui J Y, Sy E Z, Balanay M et al. Liver fat imaging-a clinical overview of ultrasound, CT, and MR imaging. The British journal of radiology 2018; 91 :

20170959.doi: https://doi.org/10.1259/bjr.20170959

8. Esterson Y B, Grimaldi G M. Radiologic imaging in nonalcoholic fatty liver disease and nonalcoholic steatohepatitis. Clinics in liver disease.2018;22:93-

108.doi: https://doi.org/10.1016/j.cld.2017.08.005

9. Middleton M S, Haufe W, Hooker J, Borga M, Leinhard O D, Romu T et al. Quantifying Abdominal Adipose Tissue and Thigh Muscle Volume and Hepatic Proton Density Fat Fraction: Repeatability and Accuracy of an MR Imaging-based, Semiautomated Analysis Method. Radiology. 2017; 283 : 438-49. doi: https://doi.org/10.1148/radiol.2017160606

10. FAT D M R I L. Role of Dixon MRI in Quantification of Liver Fat in Non-Alcoholic Fatty Liver Disease. IRAQI POSTGRADUATE MEDICAL JOURNAL 2019; 18: 305-12.

11. CAI H S, ZHAI F Y, YANG J, Dong Z, Zheng K G, Hong X F et al. MR Quantifnication of Total Liver Fat in Patients with Impaired Glucose Tolerance and with Normal Tolerace. Journal of Sun Yat-Sen University (Medical sciences) .2015; 36: 396-402.

12. Engjom T, Kavaliauskiene G, Tjora E, et al. Sonographic pancreas echogenicity in cystic fibrosis compared to exocrine pancreatic function and pancreas fat content at Dixon-MRI. PloS one 2018; 13 : e0201019. doi: https://doi.org/10.1371/journal.pone.0201019

13. Dong Z, Luo Y, Zhang Z, Cai H S, LI Y B, Chan T, et al. MR quantification of total liver fat in patients with impaired glucose tolerance and healthy subjects. PLoS One 2014;

9: e111283.doi: https://doi.org/10.1371/journal.pone.0111283

14. Samuel V T, Shulman G I. Nonalcoholic fatty liver disease as a nexus of metabolic and hepatic diseases. Cell metabolism 2018; 27: 22-41.doi: https://doi.org/10.1016/j.cmet.2017.08.002

15. Mu W, Cheng X, Liu Y, Lv Q Z, Liu G L, Zhang J G et al. Potential nexus of non-alcoholic fatty liver disease and type 2 diabetes mellitus: Insulin resistance between hepatic and peripheral tissues. Frontiers in pharmacology 2019; 9: 1566. doi: https://doi.org/10.3389/fphar.2018.01566

16. Feng Y, Dong B, Wang Y, Zhang S J, Chen S G, Ju S H. Quantification of Organ Fat Deposits in Patients with Type 2 Diabetes Mellitus by Magnetic Resonance Imaging. Chinese Journal of Medical Imaging. 2017; 25: 509-512.

17. Lu T, Wang Y, Dou T, Xue B Z, Tan Y Y, Yang J. Pancreatic fat content is associated with $\beta$-cell function and insulin resistance in Chinese type 2 diabetes subjects. Endocrine journal 2019; 66: 265270. doi: https://doi.org/10.1507/endocrj.EJ18-0436

18. Guglielmi V, Sbraccia P. Type 2 diabetes: Does pancreatic fat really matter?.Diabetes/metabolism research and reviews 2018; 34: e2955. doi: https://doi.org/10.1002/dmrr.2955

19. Matsumoto S, Mori H, Miyake H, Takaki H, Meada T, Yamada Y et al. Uneven fatty replacement of the pancreas: evaluation with CT. Radiology 1995; 194: 453-8.

doi: https://doi.org/10.1148/radiology.194.2.7824726

Page $17 / 21$ 
20. Anoop S, Misra A, Bhatt S P, Gulati S, Mahajan H. High fasting C-peptide levels and insulin resistance in non-lean \& non-obese (BMl> 19 to $<25 \mathrm{~kg} / \mathrm{m} 2)$ Asian Indians with type 2 diabetes are independently associated with high intra-abdominal fat and liver span. Diabetes \& Metabolic Syndrome: Clinical Research \& Reviews 2019; 13: 708-715.

doi: https://doi.org/10.1016/j.dsx.2018.11.041

21. Neeland I J, Turer A T, Ayers C R, Powell-Wiley T M, Vega G L, Farzaneh-Far R et al. Dysfunctional adiposity and the risk of prediabetes and type 2 diabetes in obese adults. Jama. 2012; 308: 1150-9.

22. Obata Y, Maeda N, Yamada Y, Yamamoto K, Nakamura S, Yamaokae M et al. Impact of visceral fat on gene expression profile in peripheral blood cells in obese Japanese subjects. Cardiovascular diabetology 2016;15: 159. doi: https://doi.org/10.1186/s12933-016-0479-1

23. Moh A, Neelam K, Zhang X, Sum C F, Tavintharan S, Ang K et al. Excess visceral adiposity is associated with diabetic retinopathy in a multiethnic Asian cohort with longstanding type 2 diabetes. Endocrine research 2018; 43: 186-194. doi: https://doi.org/10.1080/07435800.2018.1451541

24. Levelt E, Pavlides M, Banerjee R, Mahmod M, Kelly C, Sellwoode J t al. Ectopic and visceral fat deposition in lean and obese patients with type 2 diabetes. Journal of the American College of Cardiology 2016; 68: 53-63.

25. Lin H, Fu C, Kannengiesser S, Cheng S, Shen J, Dong H et al. Quantitative analysis of hepatic iron in patients suspected of coexisting iron overload and steatosis using multi-echo single-voxel magnetic resonance spectroscopy: Comparison with fat-saturated multi-echo gradient echo sequence. Journal of Magnetic Resonance Imaging 2018; 48: 205-213. doi: https://doi.org/10.1002/jmri.25967

26. Bonekamp S, Tang A, Mashhood A, Wolfson T, Changchien C, Middleton M Set al. Spatial distribution of MRI-determined hepatic proton density fat fraction in adults with nonalcoholic fatty liver disease. Journal of Magnetic Resonance Imaging 2014; 39: 1525-32. doi: https://doi.org/10.1002/jmri.24321

\section{Figures}




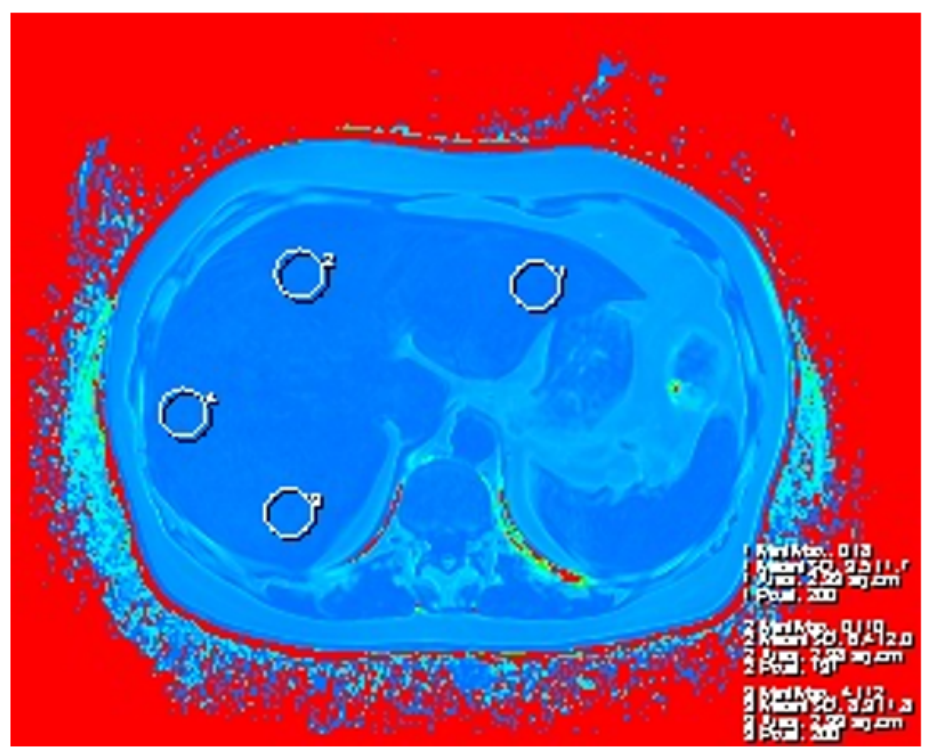

a

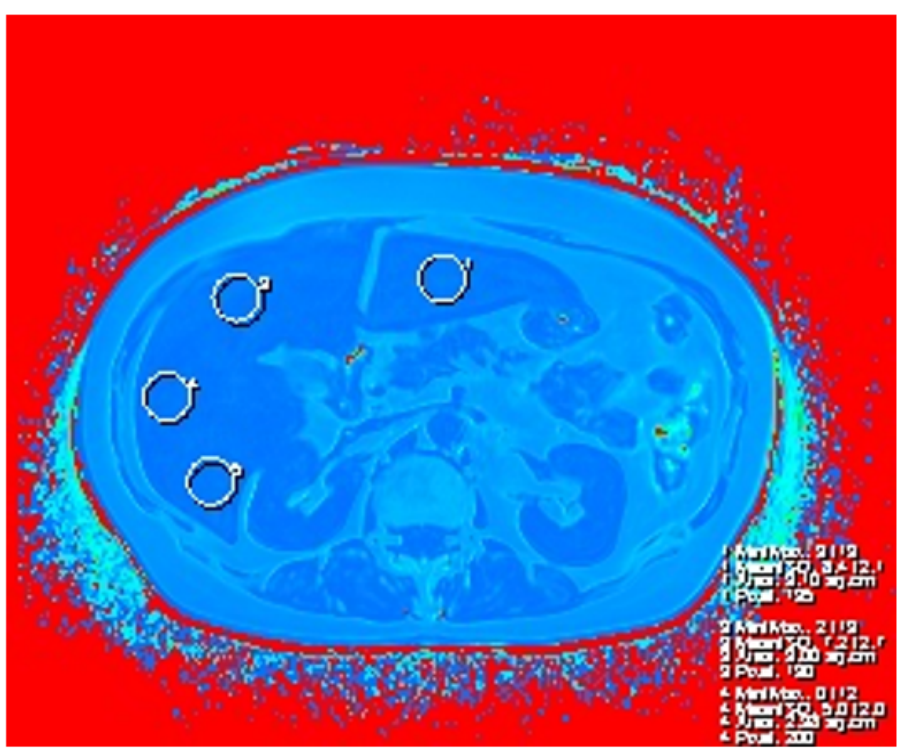

b

\section{Figure 1}

For liver, 8 regions of interest (ROIs) were depicted in left lateral lobe, left medial lobe, right anterior lobe and right posterior lobe in the slice containing main portal vein (a) and two slices below porta hepatis (b), respectively. 


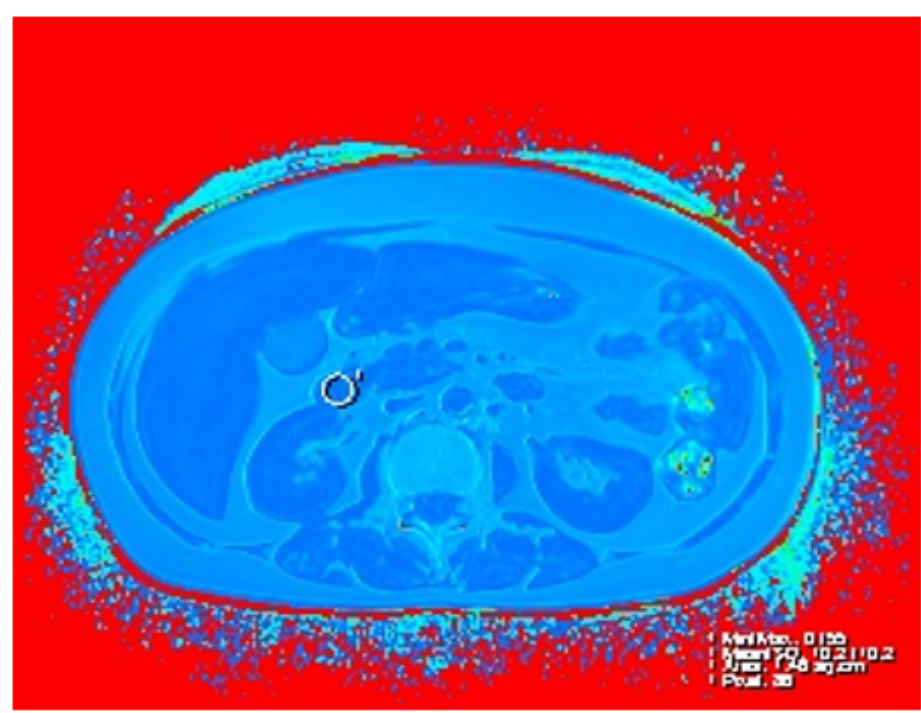

$\mathrm{a}$

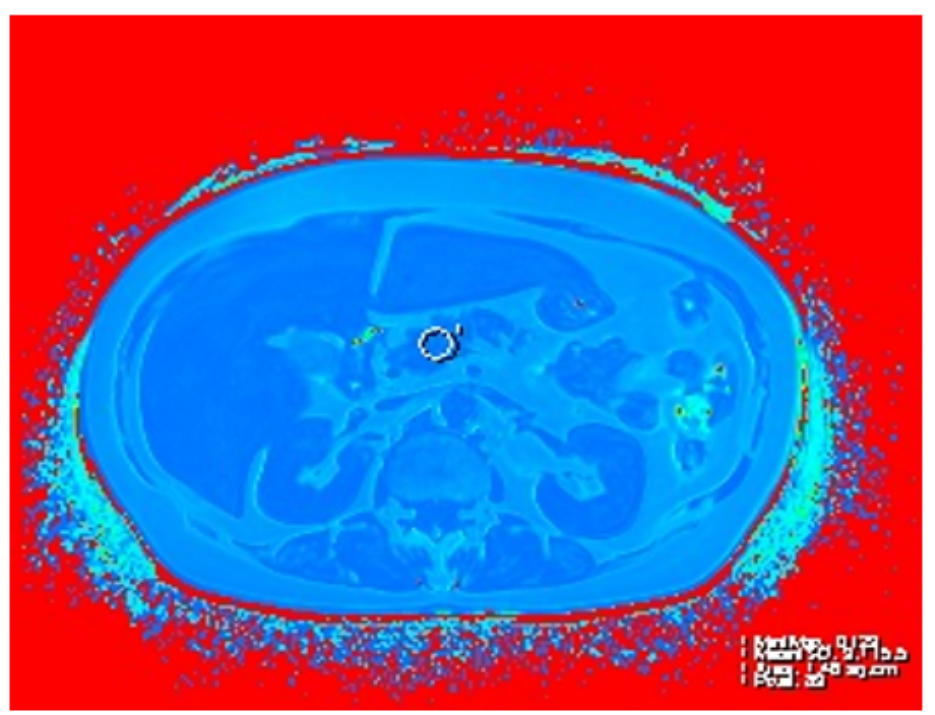

c

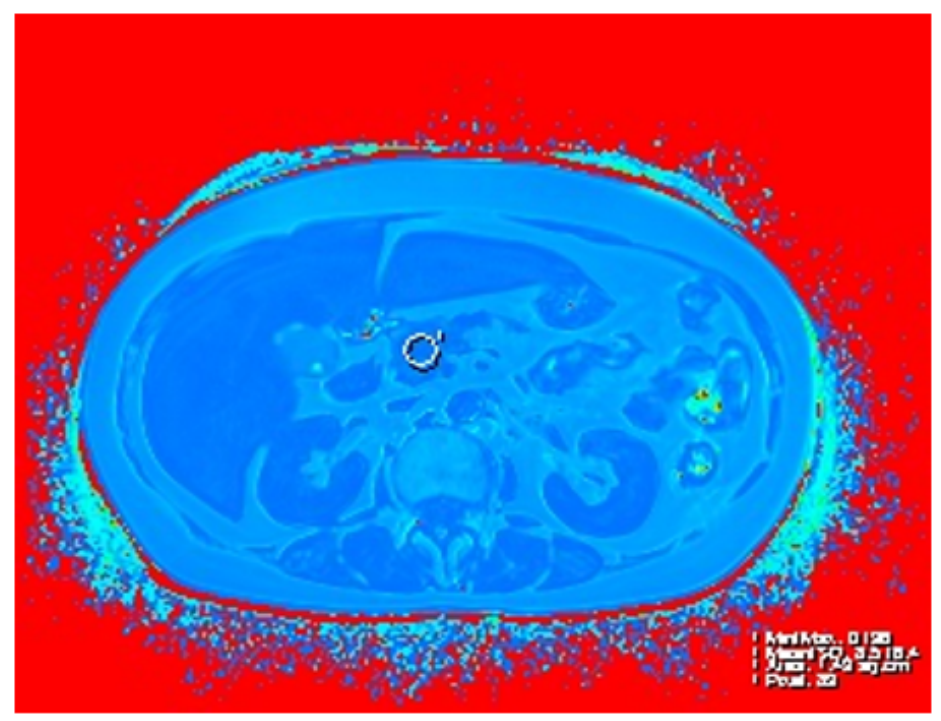

b

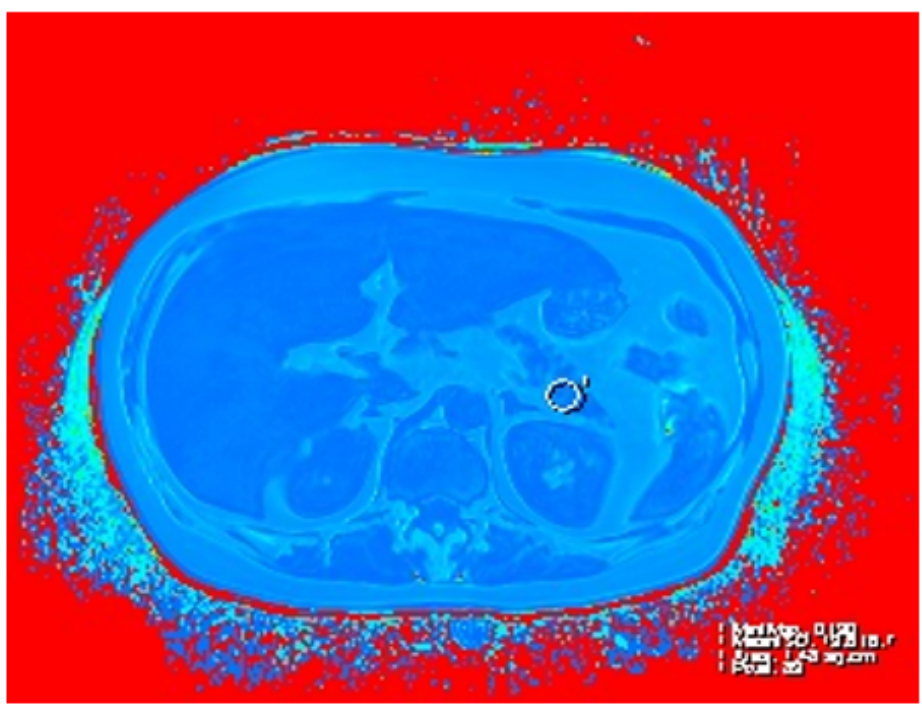

d

\section{Figure 2}

4 ROIs (with a size of around $1.5 \mathrm{~cm} 2$ ) were located in head (a), neck (b), body (c) and tail (d) of the pancreas, respectively. 


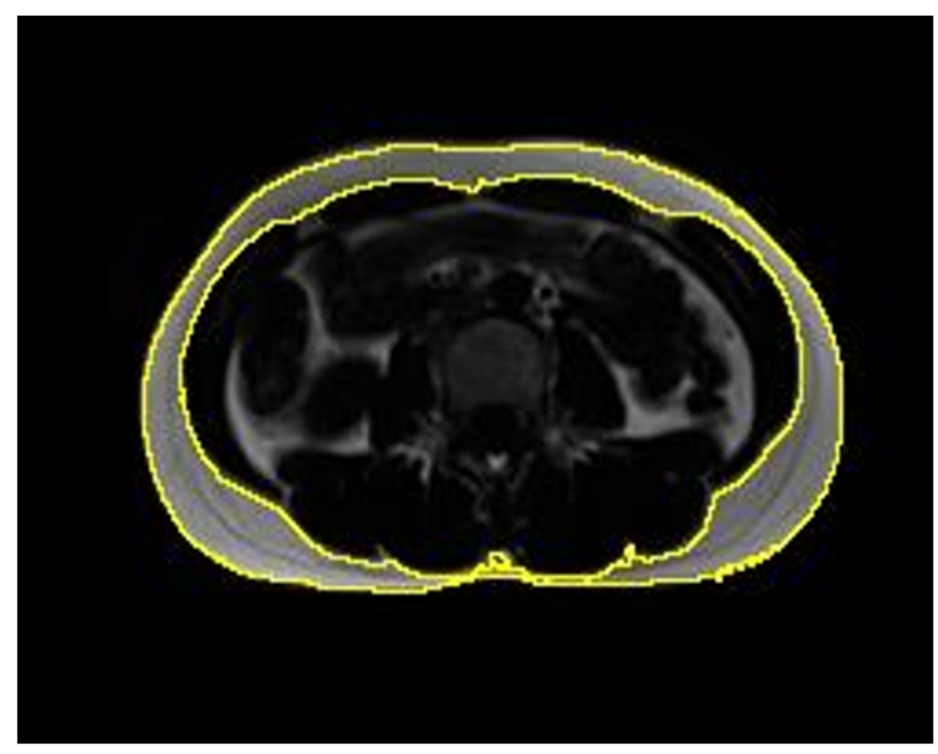

a

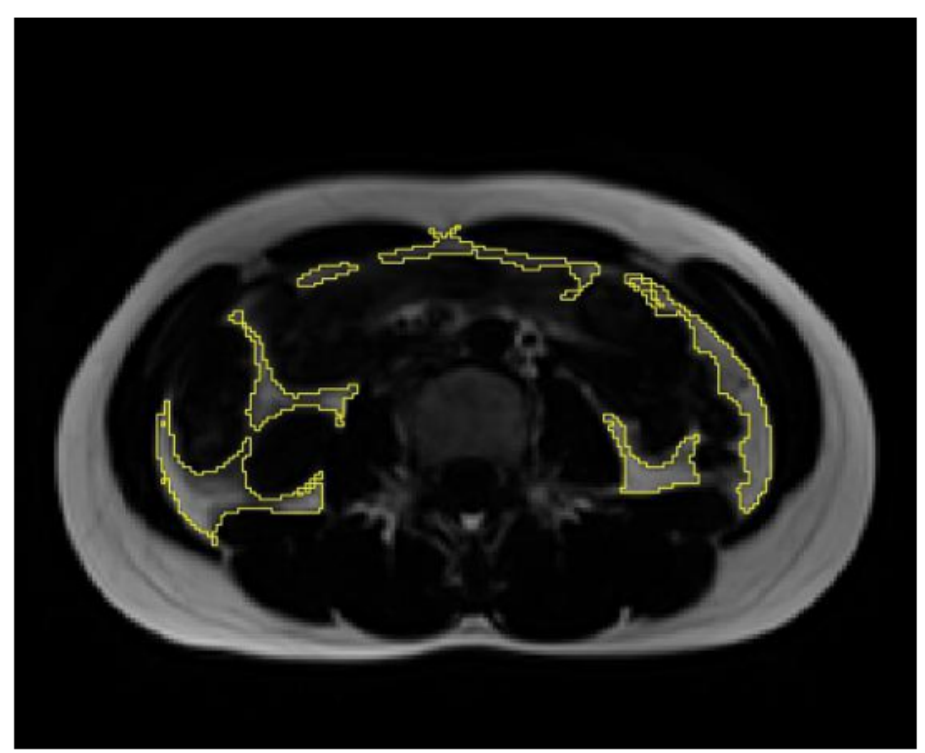

$\mathrm{b}$

\section{Figure 3}

The abdominal subcutaneous adipose area (SAT) (a) and the visceral adipose tissue area (VAT) (b) were measured using the FF image, which is $8 \mathrm{~cm}$ higher than the L4-L5 intervertebral space, by an open source software (ImageJ, https://imagej.nih.gov/ij/index.html). 